\title{
Two dimensional echocardiographic categorisation of the univentricular heart Ventricular morphology, type, and mode of atrioventricular connection
}

\author{
MICHAEL L RIGBY, ROBERT H ANDERSON, DEREK GIBSON, \\ OWEN D H JONES, MICHAEL C JOSEPH, ELLIOT A SHINEBOURNE \\ From the Departments of Paediatrics and Cardiology, Brompton Hospital, Cardiothoracic Institute, \\ Fulham Road, London
}

SUMMARY Most univentricular hearts have two chambers in their ventricular mass, only one of which possesses an atrioventricular connection. Categorisation into univentricular heart of right, left, or indeterminate type, using two dimensional echocardiography has been successfully achieved in 122 out of 132 patients to whom this technique has been applied. Thus, right ventricular rudimentary chambers in 84 univentricular hearts of left ventricular type were shown to be anterosuperior and either to the right or left. In contrast, left ventricular rudimentary chambers in 25 univentricular hearts of right ventricular type were posteroinferior and to the right, left, or directly posterior. Thirteen univentricular hearts of indeterminate morphology were characterised by absence of a rudimentary chamber on angiography and echocardiography. The trabecular pattern of both main and rudimentary chambers were separately identified in some of the patients with univentricular hearts of right and left ventricular type and two dimensional echocardiography also illustrated the mode of atrioventricular connection, either via two atrioventricular valves, a common valve, or a valve straddling or overriding the trabecular septum. Finally it was also possible to distinguish absent atrioventricular connection from an imperforate valve in 10 patients.

A univentricular heart can be defined as one in which only one ventricular chamber possesses an atrioventricular connection or connections. ${ }^{1-4}$ Such a definition does not exclude hearts which possess a second, rudimentary, ventricular chamber, providing this chamber receives no atrioventricular connection. On the basis of the morphology of the ventricles and rudimentary chambers three distinct morphological types of univentricular heart as thus defined can then be identified. Those of left ventricular type have an anterior rudimentary chamber with right ventricular trabecular pattern. Those of right ventricular type have a posterior rudimentary chamber of left ventricular pattern. Finally, those of indeterminate type do not possess a second chamber within the ventricular mass. In each of the three morphological types thus described, the type of atrioventricular connection may be double inlet, absent right

Received for publication 2 June 1981 connection, or absent left. The mode of connection may be through two atrioventricular valves, one of which may be imperforate or straddling or overriding the trabecular septum, or through a common atrioventricular valve which may also straddle or override the trabecular septum. The role of cardiac catheterisation and $M$-mode echocardiography in the diagnosis of these features of univentricular hearts is well established. ${ }^{5-8}$ The purpose of this study was to investigate the value of two dimensional echocardiography in diagnosing the morphological types of univentricular hearts and their type and mode of atrioventricular connection.

\section{Patients and methods}

One hundred and forty patients (aged 1 day to 16 years) with a definite or tentative diagnosis of a univentricular heart were studied by echocardiography between October 1979 and June 1980. One hundred and ten had been diagnosed previously by 
cardiac catheterisation and angiography, but also included were 30 infants presenting for the first time who underwent echocardiographic examination before angiography. Two dimensional echocardiograms were performed on each patient using an Advanced Technology Laboratories wide angled mechanical sector scanner or, in 10 patients, a commercial prototype phased array system. The echocardiographic examination was carried out in such a way as to show both the type and mode of atrioventricular connection together with the position of any rudimentary chamber in the ventricular mass. This was achieved by using selective tomographic views of the heart so that each patient was examined by long-axis and short-axis views of the main chamber from the parasternal, apical, and subcostal positions. ${ }^{9}$ The long axis parasternal view was usually performed from the third or fourth left interspace in patients with laevocardia, displaying a sagittal section of the heart viewed from the left side of the supine patient. A short axis view was obtained by rotating the transducer through $90^{\circ}$ so that the plane of the ultrasonic beam was approximately perpendicular to the long axis of the main chamber at or just below the level of the atrioventricular valve or valves. With the transducer placed at the cardiac apex, the ultrasonic beam was directed superiorly and medially to transect the heart from apex to base, displaying the main ventricular chamber, its connection with the atria and the interatrial septum when present. The transducer was then rotated either clockwise or anticlockwise to bring the ultrasonic beam parallel to part of the interatrial septum thereby visualising the anterolateral and inferoposterior walls of the main chamber. By moving the transducer slightly to the right, the right sided atrium and right atrioventricular connection were visualised. Similarly the left sided atrium and its connection could be shown by slight leftward movement of the transducer. Particular attention was directed to identifying anterolateral or inferoposterior rudimentary chambers from these views. With the transducer in the subcostal position, the ultrasonic beam was directed superiorly producing a tomographic view of the heart very similar to that obtained from the apex.

In the majority of cases the echocardiograms were recorded on a video-display system which allowed repeated examination of the original real-time images. Hard copy was obtained by still-frame photography using a Polaroid camera attachment. In other cases still-frame photography was performed at the time of the examination.

\section{Results}

Two dimensional echocardiography showed the precise ventricular morphology and the type and mode of atrioventricular connection in 122 of 132 patients with univentricular hearts (Table 1). The presence and position of any rudimentary chamber was usually identified in at least two of the echocardio-

Table 1

\begin{tabular}{|c|c|c|c|c|}
\hline \multicolumn{2}{|l|}{$\begin{array}{l}\text { Univentricular } \\
\text { hearts }\end{array}$} & \multicolumn{2}{|c|}{$\begin{array}{l}\text { Ventricular morphology and type } \\
\text { of atrioventricular connection }\end{array}$} & \multirow[t]{2}{*}{ Total } \\
\hline Type & $\begin{array}{l}\text { Double } \\
\text { inlet }\end{array}$ & $\begin{array}{l}\text { Absent right } \\
\text { atrioventricular } \\
\text { connection }\end{array}$ & $\begin{array}{l}\text { Absent left } \\
\text { atrioventricular } \\
\text { connection }\end{array}$ & \\
\hline Left & 46 & 37 & 1 & 84 \\
\hline Right & 9 & 1 & 15 & 25 \\
\hline Indeterminate & 12 & 0 & 1 & 13 \\
\hline
\end{tabular}

graphic planes, but in five cases could be seen only in one. In eight cases, an angiographic diagnosis of univentricular heart was not confirmed. In four of these, two with imperforate right and two with imperforate left atrioventricular valves, echocardiography showed atrioventricular concordance. The diagnosis of imperforate right atrioventricular valve was confirmed at operation in one of these patients. In one case a straddling right atrioventricular valve was shown to be predominantly connected to an anterior and right-sided ventricle. Consequently an angiographic diagnosis of double inlet univentricular heart became an echocardiographic diagnosis of atrioventricular concordance. Finally, a rim of ventricular septum extending to the crux was seen in three patients considered to have a univentricular heart, thus excluding these hearts from the study.

\section{UNIVENTRICULAR HEARTS OF LEFT VENTRICULAR TYPE (Table 2)}

These were the commonest examples of univentricular hearts studied. In 84 of 94 cases, the anterior septum separating the main and anterior rudimentary chambers was demonstrated (Fig. 1). The diagnostic feature of these hearts was that the atrioventricular connection or connections were identified posterior to the septum present in the ventricular mass. In hearts with double inlet ventricle, the rudimentary chamber

Table 2 Univentricular hearts of left ventricular morphology: type and mode of atrioventricular connection

\begin{tabular}{|c|c|c|c|}
\hline Double inlet & 46 & $\left\{\begin{array}{l}\text { Two AV valves } 38 \\
\text { Common AV valve }\end{array}\right.$ & $\left\{\begin{array}{l}\text { Straddling right } 3 \\
\text { Imperforate right } 2\end{array}\right.$ \\
\hline $\begin{array}{l}\text { Absent right } \\
\text { Absent left }\end{array}$ & $\begin{array}{c}37 \\
1\end{array}$ & & \\
\hline
\end{tabular}



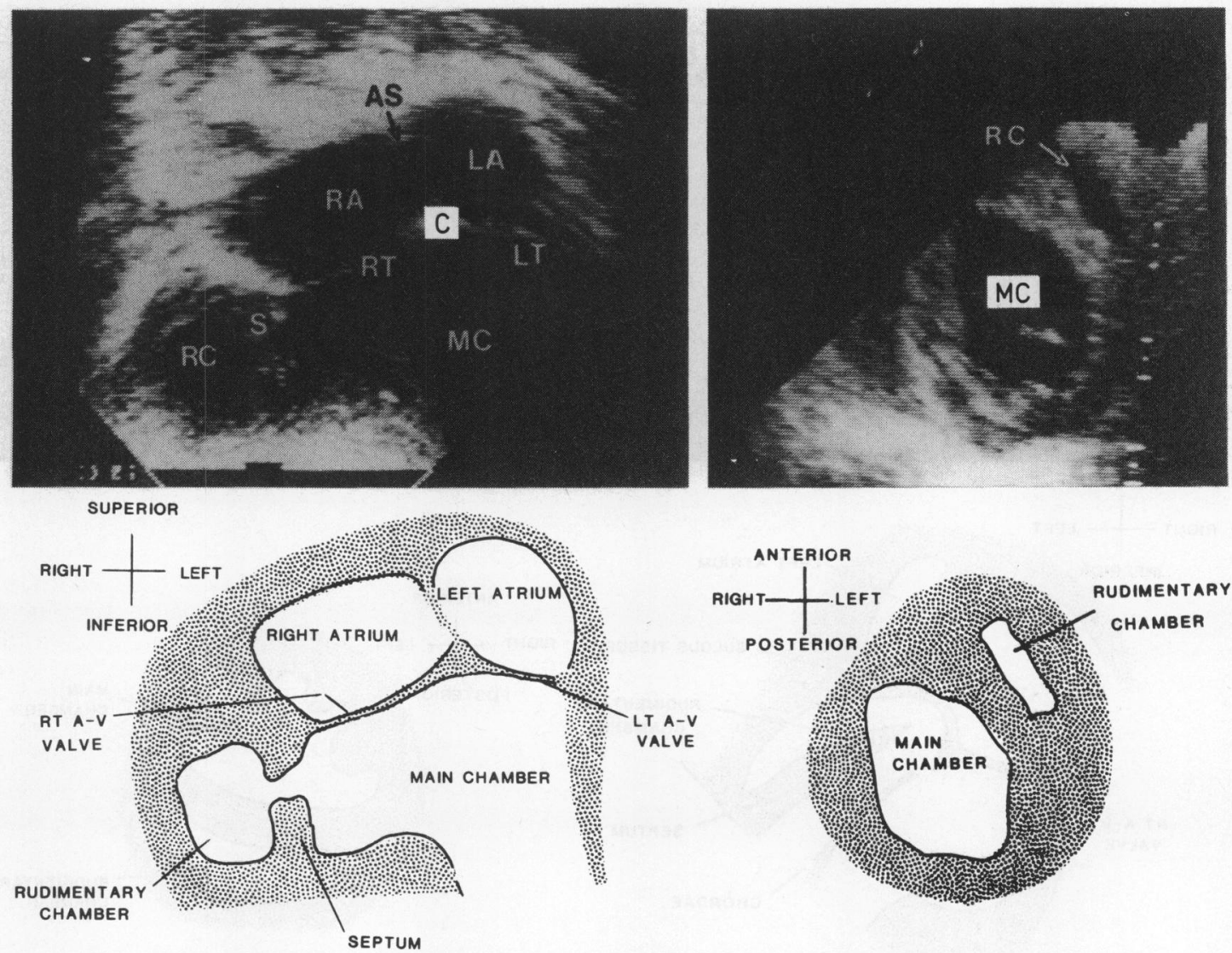

(a)

(b)

Fig. 1 (a) Apical view of double inlet univentricular heart of left ventricular morphology with two atrioventricular valves. There is an anterior and right sided rudimentary chamber $(R C)$ separated from the main chamber $(M C)$ by the trabecular septum $(S)$. The right atrium $(R A)$ connects through the right atrioventricular valve $(R T)$ to the main chamber, and is separated from the left atrium $(L A)$ by the atrial septum $(A S)$. The left atrium connects through a left atrioventricular valve $(L T)$ with the main chamber. Both the right and left atrioventricular valves connect to the central fibrous body $(C) . \quad$ (b) Short axis view of a univentricular heart of left ventricular morphology showing an anterior and left sided rudimentary chamber $(R C)$ and a smooth walled main chamber (MC).

was found to be to the right or left in approximately equal frequencies (Fig. 1; Table 3). In those hearts with absent right atrioventricular connection the rudimentary chamber was usually right sided while in the one heart with absent left connection there was a left sided trabecular pouch. While it was sometimes possible to identify the smooth trabecular pattern of the main chamber or the coarse trabecular pattern of

Table 3 Position of rudimentary chamber

\begin{tabular}{|c|c|c|c|c|c|c|}
\hline \multirow{2}{*}{$\begin{array}{l}\text { Type of } \\
\text { univentricular } \\
\text { heart }\end{array}$} & \multicolumn{3}{|c|}{ Anterior } & \multicolumn{3}{|c|}{ Posterior } \\
\hline & Left & Right & $\begin{array}{l}\text { Directly } \\
\text { anterior }\end{array}$ & Left & Right & $\begin{array}{l}\text { Directly } \\
\text { posterior }\end{array}$ \\
\hline $\begin{array}{l}\text { Left } \\
\text { Right }\end{array}$ & 27 & 55 & 2 & 1 & 19 & 5 \\
\hline
\end{tabular}

the rudimentary chamber (Fig. 1), such features could not be unequivocally shown in 45 of the 94 patients studied.

\section{UNIVENTRICULAR HEARTS OF RIGHT} VENTRICULAR TYPE (Table 4)

The pathognomic feature of these hearts was the finding of a septum posterior to the atrioventricular

Table 4 Univentricular hearts of right ventricular morphology: type and mode of atrioventricular connection

\begin{tabular}{ll}
\hline Double inlet 9 & $\left\{\begin{array}{l}\text { Two AV valves } 6 \\
\text { Common AV valve }\end{array} \quad \begin{array}{l}\text { Straddling left } 2 \\
\text { Imperforate left } 2\end{array}\right.$ \\
$\begin{array}{l}\text { Absent right } 1 \\
\text { Absent left } 15\end{array}$ & \\
\hline
\end{tabular}




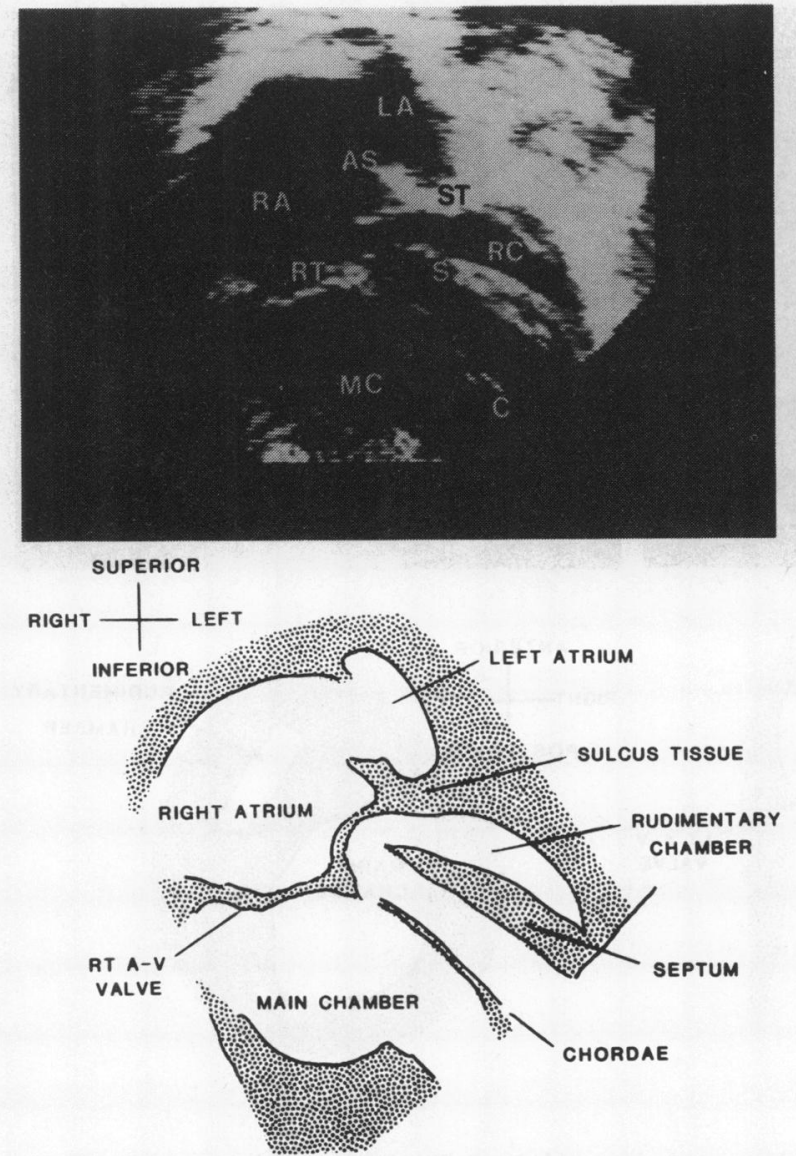

(a)

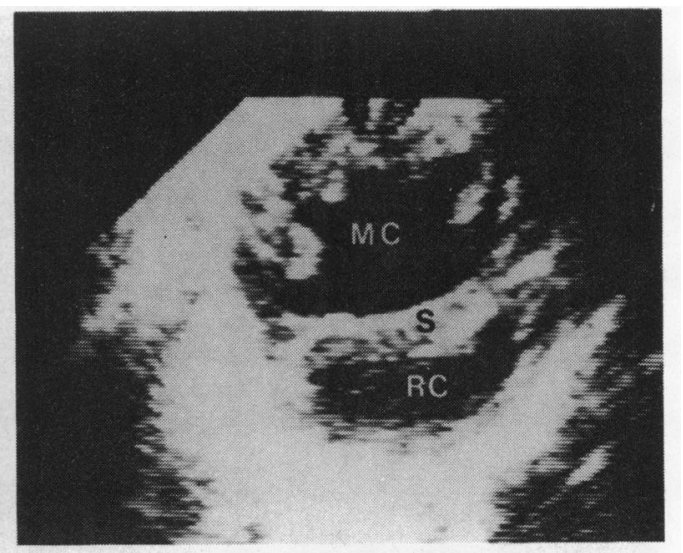

Fig. 2 (a) Apical view of univentricular heart of right ventricular morphology. There is a posterior and left sided smooth walled rudimentary chamber of left ventricular trabecular pattern $(R C)$ separated from the main chamber $(M C)$ by the trabecular septum $(S)$. The right atrium $(R A)$ connects with the main chamber through the right atrioventricular valve $(R T)$ whose tensor apparatus $(C)$ can be seen. There is an absent left atrioventricular connection; therefore there is no potential communication between the floor of the left atrium $(L A)$ and the ventricular mass, sulcus tissue (ST) interposing. Only the inferior portion of the atrial septum $(A S)$ can be visualised because there is a large atrial septal defect. (b) Short axis view of a univentricular heart of right ventricular morphology. There is a coarsely trabeculated anterior main chamber $(M C)$ and the rudimentary chamber $(R C)$ of left ventricular trabecular pattern is directly posterior and separated from the main chamber by the trabecular septum $(S)$.

connection or connections. In each of the 25 hearts studied the trabecular septum separating the main chamber from the posterior rudimentary chamber was directed towards the crux of the heart (Fig. 2). Left sided or directly posterior rudimentary chambers were predominant (Table 3; Fig. 2). The smooth trabecular pattern of the outlet chamber or trabecular pouch was evident in 16 of the 25 cases studied, while the coarse trabeculations of the main chamber could be identified with certainty only in 10 (Fig. 2). UNIVENTRICULAR HEARTS OF INDETERMINATE TYPE (Table 5)

These were hearts in which no rudimentary chamber could be demonstrated either by angiography or by echocardiography in any of the planes.

Table 5 Univentricular hearts of indeterminate morphology: type and mode of antrioventricular connection

Double inlet $12\left\{\begin{array}{llll}\text { Two } A V \text { valves } 5 & \text { Imperforate left } 2\end{array}\right.$

Absent right 0 Common AV valve 5 

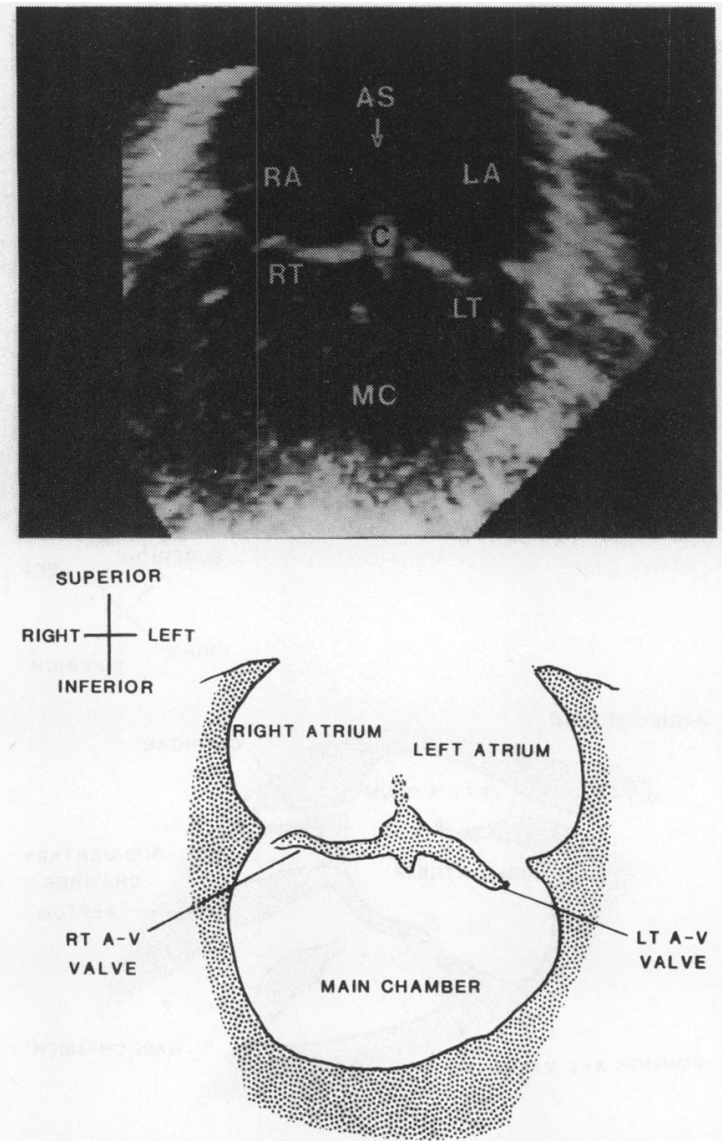

Fig. 3 Apical view of double inlet univentricular heart with two atrioventricular valves. The right atrium $(R A)$ and the left atrium $(L A)$ each connect to the main chamber $(M C)$ through the right $(R T)$ and left $(L T)$ atrioventricular valves, respectively. The valves are in continuity through the central fibrous body $(C)$. (AS, atrial septum).

TYPE OF ATRIOVENTRICULAR CONNECTION Two-dimensional echocardiography showed the type of atrioventricular connection, either double inlet (Fig. 3) or absent right or left connection (Fig. 4 and 5). Double inlet was characterised by both atria being in direct or potential communication with the main ventricular chamber. The characteristic of the hearts with absent right connection was the presence of a single, left sided atrioventricular valve and absence of any potential communication between the floor of the right atrium and the main or rudimentary ventricular chamber. Characteristically a wedge of sulcus tissue was interposed between the right atrium and the main

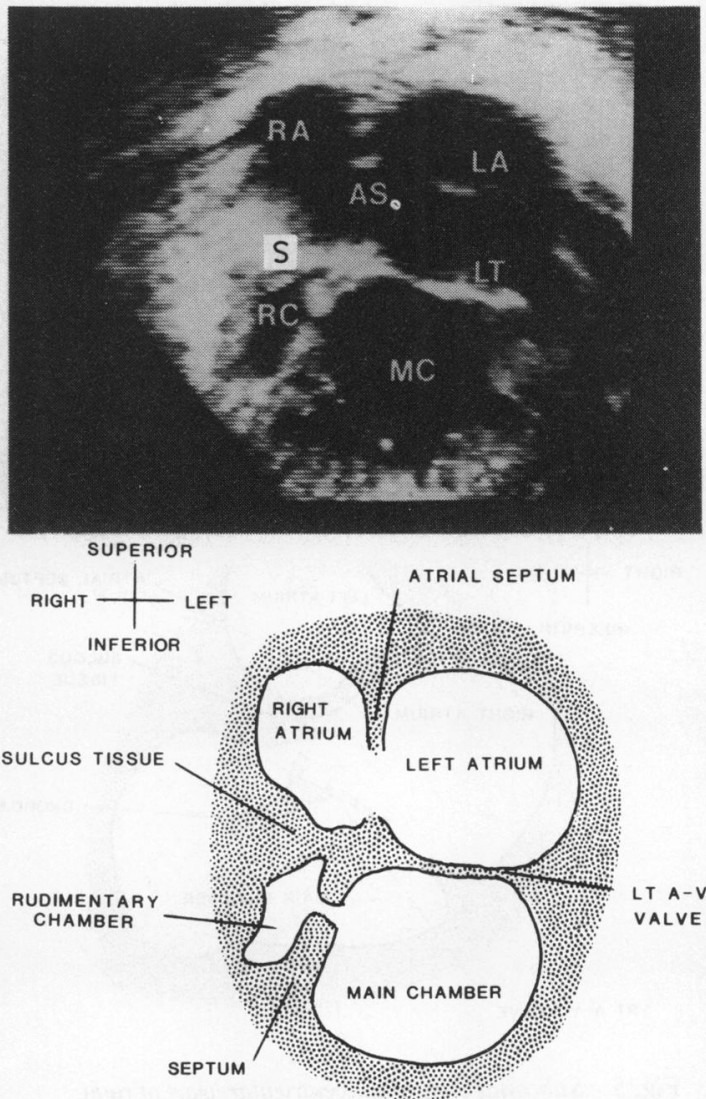

Fig. 4 Apical view of univentricular heart of left ventricular morphology with an absent right atrioventricular connection. There is no potential connection between the right atrium $(R A)$ and the ventricular mass, and sulcus tissue $(S)$ is seen interposing. The left atrium (LA) connects with the main chamber $(M C)$ through a single left atrioventricular valve (LT).The rudimentary chamber $(R C)$ is anterior and right sided. ( $A S$, atrial septum).

chamber. Similarly in hearts with absent left connection, there was a single, right sided atrioventricular valve and no potential communication between the left atrium and the ventricular mass, sulcus tissue again interposing.

MODE OF ATRIOVENTRICULAR CONNECTION When the heart was viewed from the apex or subcostal positions, the mode of atrioventricular connection was consistently demonstrated. In double inlet univentricular heart with two atrioventricular valves (Fig. 3), 


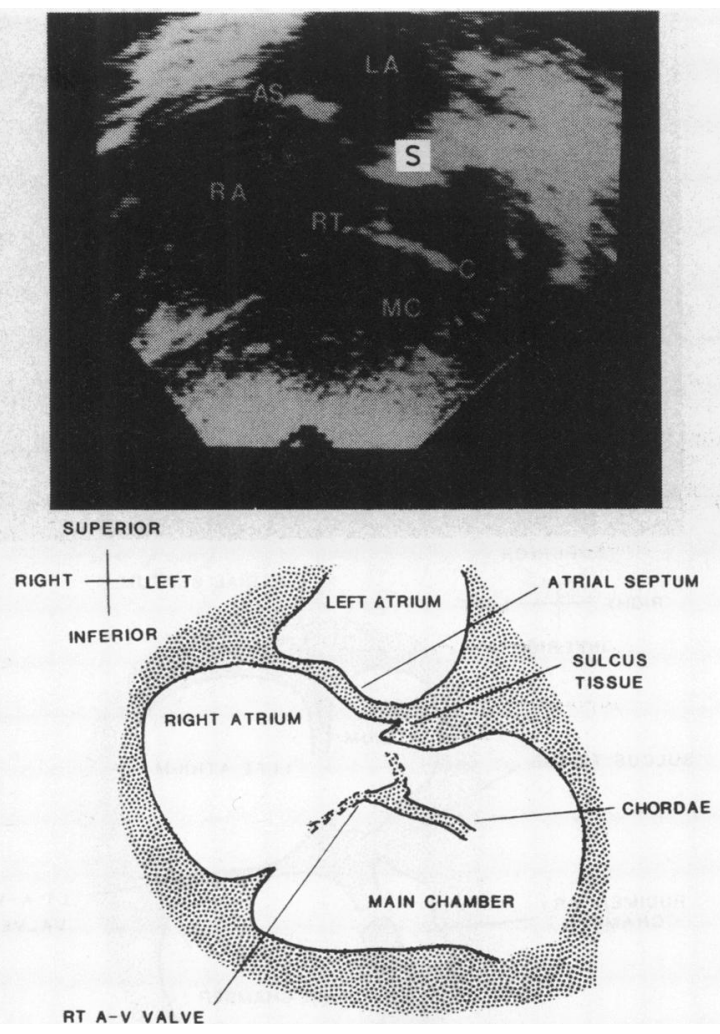

Fig. 5 Subcostal view of univentricular heart of right ventricular morphology with absent left atrioventricular connection. There is no potential communication between the floor of the left atrium (LA) and the main ventricular mass, sulcus tissue $(S)$ interposing. The right atrium $(R A)$ connects with the main chamber $(M C)$ through the right atrioventricular valve $(R T)$, which is seen supported by its own tensor apparatus $(C)$. (AS, atrial septum).

there was a characteristic motion of the medial leaflets of each valve producing diastolic appostion. On some occasions, only one valve was seen in any given echocardiographic plane. In these cases, without multiple views, the connection could be misconstrued as common inlet, imperforate right or left, or even absent connection. A large common atrioventricular valve (Fig. 6) or an imperforate valve (Fig. 7) were usually easily recognised, however, the latter being characterised as a membrane separating an atrium from the main chamber. In some instances the membrane was seen to balloon into the main chamber during diastole and in addition the tensor apparatus of the imperforate valve was identified in three cases. Thus, in six hearts considered to exhibit absent left or
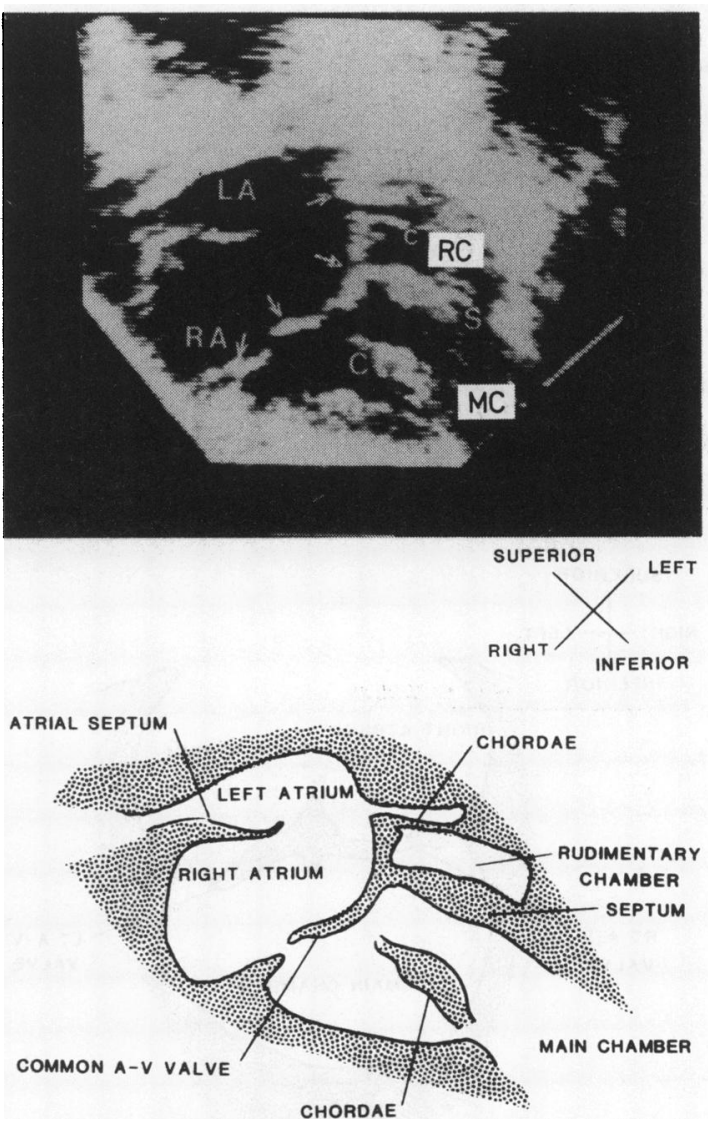

Fig. 6 Subcostal view of double inlet univentricular heart of right ventricular morphology with a common atrioventricular valve (arrows) and a posterior and left sided rudimentary chamber $(R C)$. The atrioventricular valve straddles and overrides the trabecular septum $(S)$, and tensor apparatus $(C)$ is seen arising from both the rudimentary chamber and the main chamber $(M C)$. The right atrium $(R A)$ and left atrium $(L A)$ communicate through a large primum atrial septal defect. The atrial septum $(A S)$ is malaligned to the trabecular septum.

right atrioventricular connection on angiography, two-dimensional echocardiography clearly showed double inlet univentricular heart in which the mode of connection was through one perforate and one imperforate valve. In $\mathbf{3 0}$ of the patients with rudimentary chambers, one or other of the atrioventricular valves or part of a common valve was seen to override the trabecular septum to a minor degree (Fig. 6). In all these cases the degree of override was such that the atrioventricular connection was unequivocally double 

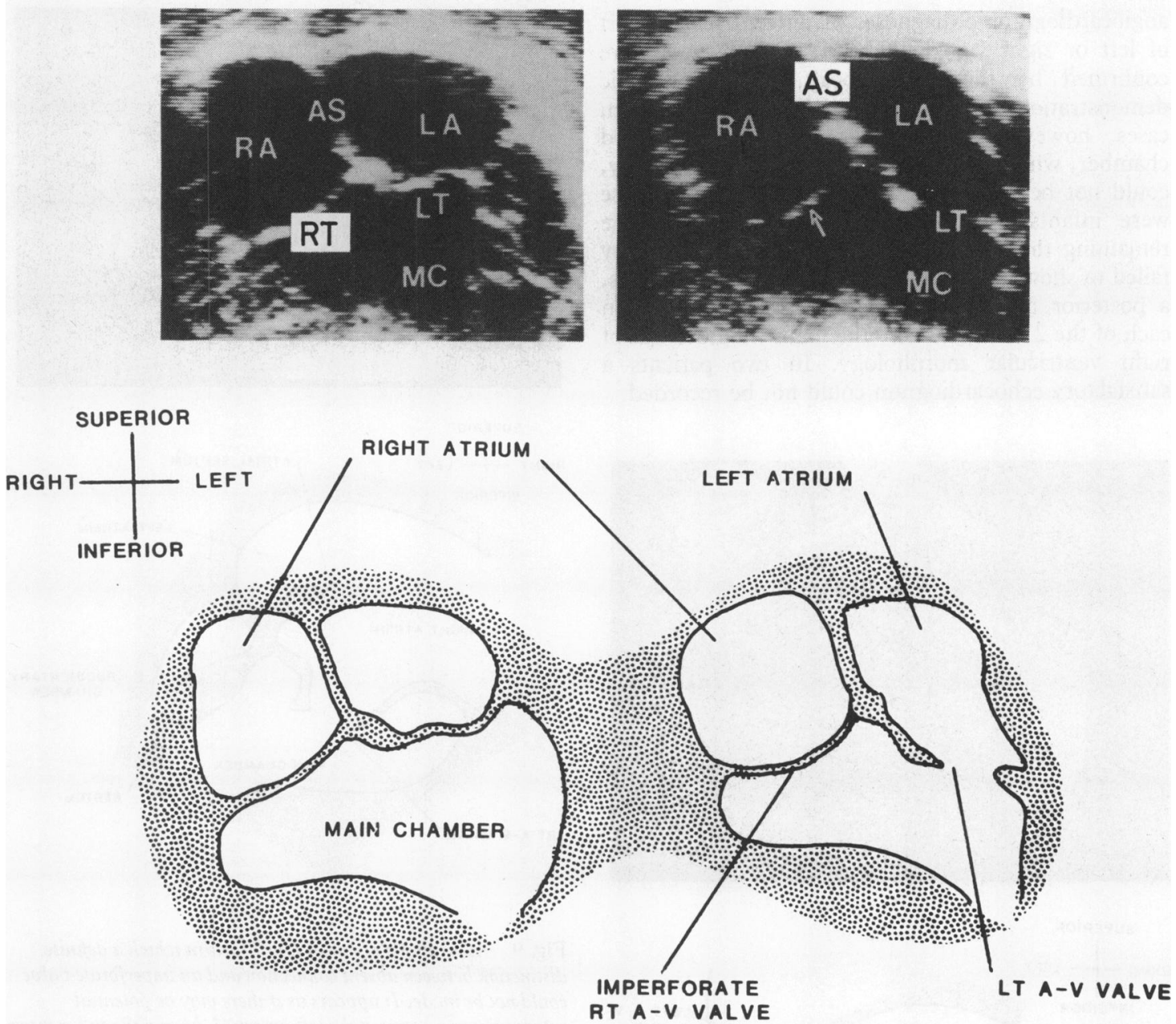

(a)

(b)

Fig. 7 (a) Apical view of double inlet univentricular heart with two atrioventricular valves recorded in systole. The right atrium $(R A)$ and left atrium $(L A)$ connect to the main chamber $(M C)$ through the right $(R T)$ and left $(L T)$ atrioventricular valves, respectively ( $A S$, atrial septum). (b) Apical view of the same heart recorded during diastole and showing an imperforate right atrioventricular valve (arrow).

inlet. In a further 10 cases, an atrioventricular valve was seen to straddle and override the septum (Fig. 8) so that tensor apparatus could be identified arising from both the main and rudimentary chambers.

\section{PROBLEM CASES}

One infant, in whom both the angiographic and echocardiographic diagnosis had been double inlet univentricular heart of left ventricular type with a common atrioventricular valve, was found at necropsy to have an atrioventricular defect with a hypoplastic right ventricle. A second infant was confidently diagnosed as having a univentricular heart of right ventricular type with a common atrioventricular valve by both selective angiography and two dimensional echocardiography. Necropsy, however, disclosed an absent left atrioventricular connection. Two patients were each thought to have two atrioventricular valves on selective angiography but two dimensional echocardiography showed a common valve. Equivocal 
angiocardiographic diagnoses of univentricular heart of left or right ventricular type in five cases were confirmed by the unequivocal echocardiographic demonstration of a rudimentary chamber. In seven cases, however, the anterior rudimentary second chamber, which had been identified on angiography, could not be convincingly visualised. Four of these were infants weighing under $4.5 \mathrm{~kg}$ and in the remaining three, two dimensional echocardiography failed to show a trabecular pouch. In contrast to this, a posterior rudimentary chamber was identified in each of the 25 hearts where the main chamber was of right ventricular morphology. In two patients a satisfactory echocardiogram could not be recorded.
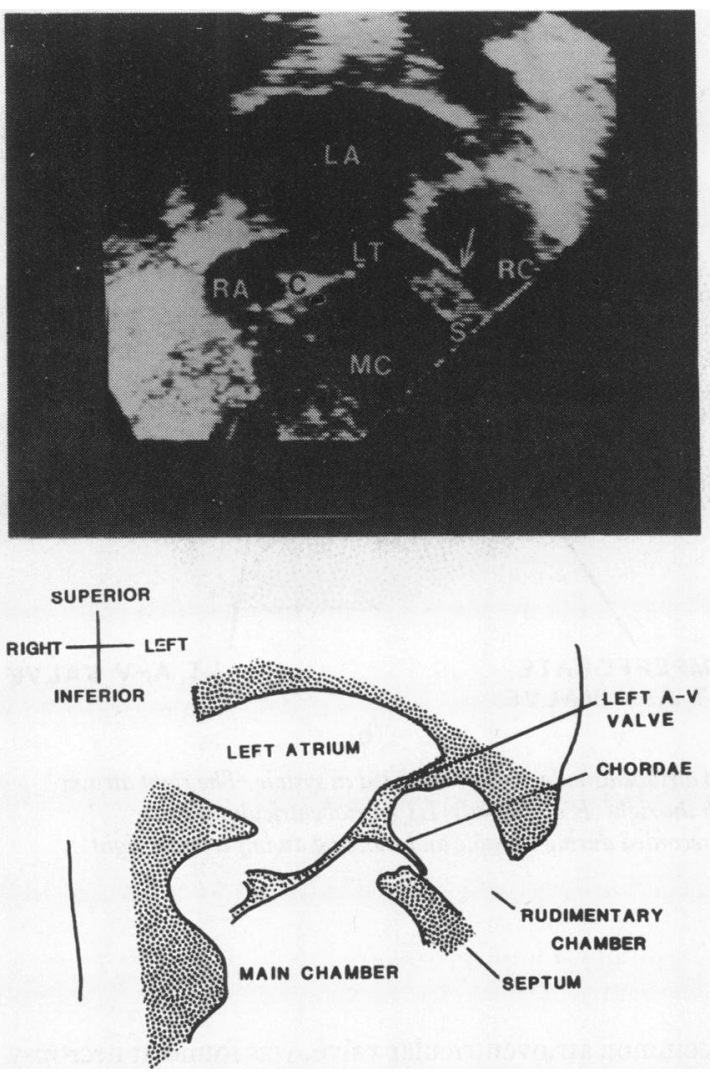

Fig. 8 Double inlet univentricular heart of right ventricular morphology with a posterior and left sided rudimentary chamber (RC) and a straddling and overriding left atrioventricular valve which is inserted into the central fibrous body $(C)$. This systolic frame shows that more than 50 per cent of the left atrioventricular valve ( $L T)$ is committed to the main chamber $(M C)$, but tensor apparatus (arrow) is seen arising from the left side of the trabecular septum $(S)(L A$, left atrium; $R A$, right atrium).
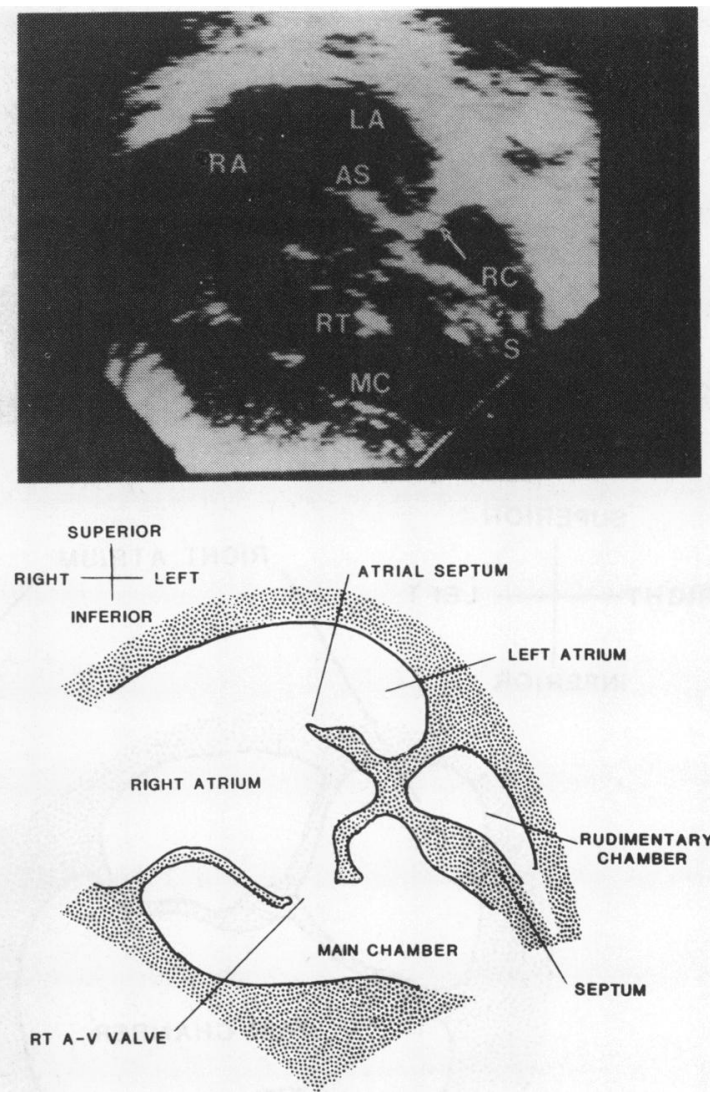

Fig. 9 An example of one of four hearts in which a definite distinction between absent connection and an imperforate valve could not be made. It appears as if there may be potential communication between the left atrium (LA) and the rudimentary chamber of left ventricular morphology $(R C)$. An arrow indicates what could be either a thick imperforate valve or sulcus tissue interposing between the left atrium and the ventricular mass. No tensor apparatus can be seen and there is clearly not a thin imperforate membrane. This heart is therefore considered to be an example of a univentricular heart of right ventricular morphology. ( $R A$, right atrium; $R T$, right atrioventricular valve; $M C$, main chamber; $S$, trabecular septum; $A S$, atrial septum).

\section{Discussion}

The classification of univentricular hearts used in this study departs from that used by others, particularly in that we have included hearts as univentricular when the main chamber pattern is that of right ventricular type but in which a second left ventricular chamber lacks an atrioventricular connection. ${ }^{10}$ We have also included as univentricular those hearts with absence 
of the right or left atrioventricular connection. ${ }^{4}$ If a right atrium or a left atrium was found to be separated by an imperforate valve from a chamber in the ventricular mass which did not receive a second atrioventricular valve, then such a heart was considered to exhibit atrioventricular concordance or discordance and was excluded from the category of univentricular heart. In addition, we excluded from the univentricular category, hearts in which the main chamber had a trabecular pattern of right ventricular type on one side, and left ventricular type on the other, the trabecular portions being separated by a hypoplastic but discrete trabecular septum. In this way, the classification used here links together all those hearts in which the atria are connected to only one chamber in the ventricular mass. Our study shows that this distinction is readily made using two dimensional echocardiography. Moreover, the different categories making up the whole are readily separated. The corner stone of this subcategorisation by two dimensional echocardiography is the identification of the presence and position of a rudimentary chamber within the ventricular mass. Posterior chambers in univentricular hearts of right ventricular type are the most easily seen. Anterior chambers in hearts of left ventricular trabecular pattern are also readily identified in the majority of cases, though a painstaking search using multiple echocardiographic planes is sometimes required.

The unequivocal demonstration of a rudimentary second chamber, and in particular, identifying its position either to the right or left can be difficult, and therefore a detailed systematic approach using each tomographic plane is essential in the investigation of any patient. Undoubtedly the apical and subcostal views are the most useful in identifying an outlet chamber or trabecular pouch. It is important, however, to obtain an image with the ultrasonic plane both at right angles to and parallel to part of the interatrial septum, or in similar positions when there is no septum. In univentricular hearts of right ventricular morphology, posterior left ventricular rudimentary chambers are almost always to the left or directly posterior and can therefore be identified when the echocardiographic plane is at right angles to the interatrial septum in the classical apical and subcostal views. A similar view will allow the identification of a right-sided anterior right ventricular rudimentary chamber in univentricular hearts of left ventricular morphology. To demonstrate a left sided rudimentary chamber in univentricular hearts of left ventricular type (Fig. 1), however, or a right sided chamber in univentricular hearts of right ventricular type, the echocardiographic plane should be approximately parallel to the interatrial septum.

When a second rudimentary ventricular chamber is seen on a short axis view at or just below the level of the atrioventricular valves, its position relative to the main chamber is easily defined. Unfortunately, in infants an anterior chamber is frequently not identified when this view is used to examine univentricular hearts of left ventricular morphology. Failure to show an anterior chamber in small infants in some echocardiographic planes reflects the resolution of the instrument used. When it is impossible either by angiography or by echocardiography to define a second chamber within the ventricular mass then it is most likely that the ventricular morphology is of indeterminate type. Either echocardiography or angiography, however, may fail to demonstrate a small second chamber which may subsequently be found at necropsy. In such cases, from a clinical standpoint, hearts of left or right ventricular type effectively exist without a rudimentary chamber. None the less, with a $5 \mathrm{MHz}$ transducer the modern ultrasonoscope will allow the delineation of exceedingly hypoplastic chambers and lateral resolution of 2 to $3 \mathrm{~mm}$ should be possible.

Confusion can arise in diagnosis when, in some instances, thickened tensor apparatus is seen in the main chamber (Fig. 6). It can be mistaken for an interventricular septum unless its attachment to the atrioventricular valve leaflets is positively identified.

Further potential difficulties exist in the echocardiographic classification of univentricular hearts because the rudimentary chamber may not be entirely anterior in position, or less significantly may not be confined completely to the left or right. ${ }^{1}$ For example, in univentricular hearts of left ventricular type, the apex of the rudimentary chamber may be posterior while its infundibular portion is unequivocally anterior. None the less, the atrioventricular connection will still be behind the septum. Similarly, while the outlet zone of an outlet chamber is to the left, the trabecular zone may be to the right. In presently describing the position of the rudimentary chambers, we have used as our reference point the atrioventricular valves. Problems also arise in distinguishing a univentricular heart with a common atrioventricular valve from a complete atrioventricular defect with a hypoplastic ventricle. The distinction in a few cases may be impossible by echocardiography and angiography. In hearts with a common atrioventricular valve we have considered those as univentricular where there is malalignment between the atrial septum and the trabecular septum. In the presence of a common atrium more than $75 \%$ of the atrioventricular valve should be committed to the main ventricular chamber.

In the majority of hearts two dimensional echocardiography unequivocally shows the type and mode of atrioventricular connection more consistently than 
selective angiography. Nevertheless, we did experience some difficulties in distinguishing an absent connection (where there is no direct continuity between atrial and ventricular myocardium) from an imperforate valve in four cases. In the majority of hearts with classical tricuspid atresia it can be clearly shown that there is no potential communication between the floor of the right atrium and the main ventricular chamber. We do not agree with the observations of some workers ${ }^{11}$ that a thick echo in the 'tricuspid area' is an invariable finding in these hearts. None the less, in three cases the distinction between absent connection or a thickened imperforate, immobile valve was difficult. Similarly in one case of univentricular heart of right ventricular morphology, we could not establish with absolute certainty whether or not there was an absent left atrioventricular connection or a thickened immobile imperforate valve (Fig. 9). We have only designated a connection as imperforate when we have identified a thin membrane or clearly shown the tensor apparatus of the valve (Fig. 7). The heart in Fig. 9 has therefore been considered as univentricular.

Two dimensional echocardiography also provides a reliable method of distinguishing overriding from straddling valves. In the former, though the atrioventricular valve is related to both the main and rudimentary chambers, all the tensor apparatus arises from the main chamber and the leaflets are seen within it during diastole. In contrast straddling valves have their tensor apparatus attached in both main and rudimentary chambers and one leaflet is sometimes but not invariably seen within the outlet chamber or trabecular pouch when the valve is open.

Our study has shown the value of two dimensional echocardiography in the diagnosis of patients in whom the atria connect to only one chamber within the ventricular mass. We have further shown that subcategorisation of these hearts depends mainly upon the demonstration of the position of a second rudimentary chamber within the ventricular mass which lacks an atrioventricular connection. The visualisation of the trabecular pattern of the main chamber or rudimentary chamber is a less reliable guide. We have also shown the value of echocardiography in defining the type and mode of atrioventricular connection. It must be emphasised, however, that the categorisation of univentricular hearts depends in addition upon the description of atrial situs, the ventriculoarterial connection, the arterial relations, and the presence of associated malform- ations. It is in the visualisation and classification of the atrioventricular junction that two dimensional echocardiography is particularly superior to conventional angiography.

\section{References}

1 Anderson RH, Tynan M, Freedom RM, et al. Ventricular morphology in the univentricular heart. Herz 1979; 4: 184-97.

2 Shinebourne EA, Macartney FJ, Anderson RH. Sequential chamber localization - logical approach to diagnosis in congenital heart disease. Br Heart $\mathcal{F}$ 1976; 38: $327-40$.

3 Tynan MJ, Becker AE, Macartney FJ, Jiménez MQ, Shinebourne EA, Anderson RH. Nomenclature and classification of congenital heart disease. Br Heart $\mathcal{F}$ 1979; 41: 544-53.

4 Wilkinson JL, Becker AE, Tynan M, et al. Nomenclature of the univentricular heart. Herz 1979; 4: 107-12.

5 Beardshaw JA, Gibson DG, Pearson MC, Upton MT, Anderson RH. Echocardiographic diagnosis of primitive ventricle with two atrioventricular valves. $\mathrm{Br}$ Heart $\mathcal{F}$ 1977; 39: 266-75.

6 Bini RM, Bloom KR, Culham JAG, Freedom RMM, Williams CM, Rowe RD. The reliability and practicality of single crystal echocardiography in the evaluation of single ventricle. Angiographic and pathologic correlates. Circulation 1978; 57: 269-77.

7 Macartney FJ, Daly K, Wilkinson JL, Anderson RH. Angiocardiography in the pre-operative evaluation of patients with univentricular hearts. Herz 1979; 4: 213-9.

8 Mortera C, Hunter S, Terry G, Tynan M. Echocardiography of primitive ventricle. $B r$ Heart $\mathcal{F} 1977$; 39: 847-55.

9 Tajik AJ, Seward JB, Hagler DJ, Mair DD, Lie JT. Two-dimensional real-time ultrasonic imaging of the heart and great vessels. Mayo Clin Proc 1978; 53: 271-303.

10 Van Praagh R, Plett JA, Van Praagh St. Single ventricle: pathology, embryology terminology and classification. Herz 1979; 4: 113-50.

11 Beppu S, Nimura Y, Tamai M, et al. Two-dimensional echocardiography in diagnosing tricuspid atresia. $\mathrm{Br}$ Heart $f$ 1978; 40: 1174-83.

Requests for reprints to Dr M L Rigby, Department of Paediatrics, Brompton Hospital, Fulham Road, London SW3 6HP. 